\title{
GILBERTO FREYRE Y SÉRGIO BUARQUE DE HOLANDA: MESTIÇAGEM Y CORDIALIDADE COMO ESTRATEGIAS DE CONVIVENCIA ${ }^{1}$
}

\author{
Horst Nitschack \\ Universidad de Chile \\ horst.nitschack@gmail.com
}

\section{RESUMEN / RESUMO / ABSTRACT}

En los años treinta del siglo XX, los autores Gilberto Freyre y Sérgio Buarque de Holanda presentaron en sus dos grandes ensayos Casa-grande \& Senzala (1933) y Raízes do Brasil (1936), respectivamente, los conceptos de mestizaje y cordialidad, que contribuyeron en forma decisiva para lo que se puede entender como 'brasileñidad'. En el presente artículo se propone leer estos dos conceptos en el contexto de la discusión sobre cuál será el papel de Brasil en el proceso de modernización y de las perspectivas y posibilidades que tiene el país para desarrollar una modernidad adecuada a sus propias condiciones históricas y culturales. Así, mestizaje y cordialidad se entienden como formas de convivencia que, a pesar de su origen problemático en la colonialidad, presentan un potencial considerable para el desarrollo de una modernidad brasileña propia.

Palabras clave: Gilberto Freyre, Sérgio Buarque de Holanda, mestizagem/mestizaje, cordialidad, convivencia.

Durante os anos 30 do século XX, os autores Gilberto Freyre e Sérgio Buarque de Holanda apresentam em seus dois grandes ensaios Casa-grande \& Senzala (1933) e Raízes do Brasil (1936) a 'mestiçagem'e a 'cordialidade', dois conceitos que contribuirão decisivamente ao que pode ser entendido como 'brasilidade'. No presente artigo, se propõe uma leitura desses dois conceitos no contexto da discussão sobre qual será o papel do Brasil no processo de

1 Este artículo es resultado de una investigación en curso, que se realiza en el contexto del Proyecto Fondecyt 1120116: Rebeldes, malandros, delincuentes y locos: resistencias, transgresiones y expectativas utópicas en la literatura brasileña del siglo XX. 
modernização e sobre as perspectivas e possibilidades que o país possui para desenvolver uma modernidade adequada as suas próprias condições históricas e culturais. Dessa forma, a 'mestiçagem' e a 'cordialidade' se entendem como formas de convivência que -apesar de sua origem problemática durante a colônia-tem uma potencialidade considerável para desenvolver uma modernidade brasileira própria.

PaLAVRAS-Chaves: Gilberto Freyre, Sérgio Buarque de Holanda, 'mestiçagem', 'cordialidade', convivência.

During the 1930s, authors Gilberto Freyre and Sergio Buarque de Holanda present in their two major works -The Masters and the Slaves (1933) and Roots of Brazil (1936) - the idea of 'miscegenation' and 'cordiality', two concepts that contribute decisively to what can be understood as 'Brazilianness'. In this article, these two concepts are interpreted within the discussion about the role of Brazil in the modernization process and the country's prospects and possibilities of developing a sense of modernity in accordance with its own historical and cultural background. Thus, 'miscegenation' and 'cordiality' are seen as forms of coexistence that, despite its problematic origin in colonial times, have considerable potential to develop its own Brazilian modernity.

KEYWORDS: Gilberto Freyre, Sérgio Buarque de Holanda, miscegenation, cordiality, coexistence.

El año 1922 fue en Brasil motivo para conmemorar el centenario de la independencia, una ocasión para celebrar la brasilidade, pero también un momento de reflexión y crítica.

Sin duda alguna, en los últimos 100 años el país ha logrado reconocimiento a nivel internacional. Logró asegurar en el continente sudamericano sus fronteras con los países vecinos sin conflictos bélicos (a excepción de la Guerra de la Triple Alianza contra Paraguay (1865-1870)) y, a su vez, (con una sola excepción, en este caso la Guayana Británica) ha resuelto a su favor todos los conflictos limítrofes. Si bien la tardía liberación de esclavos (1888) y la transición del Imperio hacia una República (1889) condujeron a diversos conflictos de carácter civil (la "Revolta da Armada" entre 1891 y 1894, y sobre todo la Guerra de Canudos), estos acontecimientos no lograron desestabilizar al país. Las exportaciones de café, caucho y cacao garantizaron a las oligarquías y a la burguesía una riqueza considerable, que permitió la modernización a gran escala de la ciudad de Río de Janeiro. A pesar de esos avances, la República, la que pronto -a partir de 1930- sería llamada " $a$ República velha", se verá enfrentada a un gran descontento, cuyo origen se encuentra en el hecho de que el país no logró cumplir con las expectativas que había despertado en sus ciudadanos en el transcurso del siglo XIX. A 
nivel nacional, es en ese entonces un país con una fuerte inequidad social y cultural, dado que la abolición formal de la esclavitud no trajo consigo la erradicación de la inequidad social y económica. Alarmantes son la tasa de analfabetismo y el nivel de miseria en las zonas rurales más apartadas, para las cuales prácticamente no existe acceso desde los centros urbanos y la costa.

A comienzos de siglo XX, dos publicaciones que difieren bastante la una de la otra concitan la atención del pequeño segmento de opinión pública culta sobre estas profundas injusticias en el país. Dichas publicaciones se centran en manifestaciones absolutamente dispares del atraso de Brasil, identificando necesariamente causas totalmente diferentes para éstas: Euclides da Cunha narra en su obra Os Sertões (1902) la historia de la Guerra de Canudos, en la que alrededor de 15.000 habitantes del Sertão (Sertón), en una resistencia abierta contra las autoridades regionales y en cuatro campañas militares, lideradas por el predicador Antonio Conselheiro, fueron finalmente aniquilados en forma brutal por parte del ejército brasileño. En A América Latina. Males de Origem (1905), Manoel Bomfim plantea claramente la pregunta acerca de las causas del atraso de Brasil, el que de ningún modo se corresponde con las ideas rectoras del país del ordem e progreso.

Mientras Euclides da Cunha insiste en la necesidad de un proceso civilizador para el país ("Estamos condenados à civilização" (Cunha 157)), reconociendo al mismo tiempo los riesgos de dicha civilización, que -al igual que en la Guerra de Canudos- puede llegar a grados de barbarie que nada tienen que envidiar a aquellos de los "no civilizados", para Bomfim aún no se ha iniciado en el país un proceso real y apropiado de civilización. Al comienzo, Euclides da Cunha se mantiene leal en sus argumentos al pensamiento positivista y, al momento de alejarse de éste, se aferra al darwinismo social de Spencer, quien ve las causas de la ausencia de progreso no solo en el clima y la situación geográfica del país, sino también en el tema racial. En cambio, Manoel Bomfim responsabiliza solamente a la política colonialista portuguesa del atraso de Brasil -y eso es precisamente lo que hace provocativo su pensamiento-a lo que el intelectual y académico descollante en esa época, Silvio Romero, reacciona con una amplia polémica, convirtiéndose Manoel Bomfim en un adelantado teórico de la colonialidad. En su concepto del "parasitismo" del colonialista (un concepto aún contaminado biológicamente, similar por cierto al concepto del "hibridismo" que nos resulta familiar), que explota al colonizado, lo somete a su poder y lo obliga a una situación de total dependencia y pasividad intelectual y moral, va también más allá del término colonialidad, ya que según Bomfim dicho parasitismo conduce 
a la decadencia y ruina del propio colonizador. Por lo tanto, para Manoel Bomfim no son "la inferioridad" de la raza indígena y de la raza negra, ni tampoco la decadencia generada por el mestizaje las responsables del atraso del país, sino solamente el parasitismo del colonialismo portugués. Como consecuencia de ello, para Bomfim la solución tampoco puede estar en una política racial en cualquiera de sus formas, ya sea que se trate del necesario blanqueamiento racial (branqueamento) - por el que aboga Silvio Romero a pesar de reconocer la importancia del aporte indígena y africano a la cultura brasileña- o de una reinterpretación positiva del mestizaje, que reconoce a la nueva raza como la raza del futuro, sino que solamente se encontraría en una política educacional amplia y profunda.

Sofremos, neste momento, uma inferioridade, é verdade, relativamente aos outros povos cultos. É a IGNORÂNCIA, é a falta de preparo e de educação para o progresso - eis a inferioridade efetiva, mas ela é curável, facilmente curável. O remédio está indicado. Eis a conclusão última desta longa demonstração: a necessidade imprescindível de atender-se à instrução popular, se a América Latina se quer salvar (Bomfim 360, énfasis suyo).

No obstante, ¿cómo se miden el atraso y la falta de civilización del país, que al constatarse en aquel entonces provocaron dicho descontento y crítica respecto al desarrollo de Brasil desde su independencia? La comparación con la metrópolis portuguesa o con las culturas europeas más importantes, cuya superioridad antes de la Primera Guerra Mundial aún es reconocida sin problema alguno (aquí Bomfim constituye una excepción con su crítica a Portugal), no puede ser el argumento. La autocrítica se genera en la comparación con un país americano, que experimentó durante el siglo XIX un desarrollo como ningún otro país en la región: los Estados Unidos de América.

Ya en la época del Imperio, Brasil comienza a compararse con Estados Unidos y a hacerse la pregunta ¿por qué Brasil, pudiendo compararse con el vecino del norte por su dimensión y posibilidades, no ha logrado un desarrollo similar en el trascurso del siglo XIX? Aquí se ven enfrentadas dos posiciones: por una parte, la admiración por los EE.UU. y la convicción de que el desarrollo de ese país debe servir de modelo para Brasil y, por otra, el rechazo radical a los EE.UU. como una forma social y económica para Brasil.

Los admiradores de los Estados Unidos son precisamente los intelectuales y políticos liberales del país que habían abogado por la abolición de la esclavitud, como por ejemplo Joaquim Nabuco. El 28 de agosto de 1908, éste 
pronuncia un discurso en la Universidad de Chicago sobre "A Aproximação das duas Américas", un amplio panegírico de los EE.UU., afirmando por ejemplo: "Vos, como toda alta civilização, não podeis fazer mal a nenhuma outra nação. O contato íntimo convosco, seja em que condições for, só poderá portanto trazer benefício e progresso à outra parte" (cit. en Rosi s/p).

El historiador, crítico literario y embajador, Manuel de Oliveira Lima, se expresa de manera similar: "Os EUA constituem o mais acabado organismo político de que temos conhecimento, nação dotada de recursos imensos, de admirável estrutura administrativa, de vigorosas qualidades privadas, raça inventiva, possante, apta para a dominação" (cit. en Lisboa 197).

Teniendo en cuenta lo anterior, es decir, la proclamación de los EE.UU. como un modelo para el desarrollo de Brasil, es dable entender a los detractores de los EE.UU., quienes posteriormente, sobre todo en los años 20 , comenzarán a adquirir mayor peso. Lo que llama la atención aquí es que la crítica a los EE.UU. es expresada fundamentalmente por intelectuales conservadores anti-republicanos, como por ejemplo por Eduardo Prado en su libro A Ilusão Americana (1893) -cuya primera edición fue prohibida y confiscada por orden del gobierno republicano-, y también en Populações meridionais do Brasil (1920) de Oliveira Vianna, quien luego se convirtiera en asesor del gobierno fascista de Getúlio Vargas.

A comienzos de los años 20 se produce un cambio decisivo. La totalidad del movimiento vanguardista brasileño (modernismo) asumirá una posición crítica frente a los EE.UU., siendo causas muy variadas las que contribuyen a desmitificar el "modelo norteamericano". En primer lugar, la Primera Guerra Mundial, que puso en duda la superioridad cultural de la civilización occidental con la que se identifica a los EE.UU. La obra de Spengler $L a$ decadencia o El ocaso de Occidente es interpretada en numerosas ocasiones como pronóstico de la decadencia contemporánea de la cultura occidental (contrariamente a la propia argumentación de Spengler); posteriormente, la Revolución rusa y el nacimiento de la Unión Soviética, junto con las crisis económica del mundo capitalista a finales de los años 20, que también tuvo consecuencias dramáticas para Brasil. Asimismo, la superación definitiva del pensamiento positivista, que a fin de cuentas significaba la justificación filosófica de la superioridad occidental y, por consiguiente, la legitimación de una política colonialista, permite que Brasil intente comprenderse e interpretarse a partir de sí mismo. Una nueva generación, que representa a un nuevo Brasil, asoma en el escenario nacional. Un Brasil que pretende liberarse definitivamente de la dependencia internacional (especialmente 
en el ámbito cultural), que intenta explicar su propia historia desde el punto de vista histórico, social y cultural a partir tanto de su problemática (Paulo Prado: Retrato do Brasil - Ensaio sobre a tristeza brasileira (1928)) como de sus posibilidades (G. Freye: Casa-grande \& Senzala (1933)), y ya no más partiendo de los paradigmas de las teorías raciales del positivismo, o un Brasil que al menos está decidido a darle a aquellas teorías raciales, como la teoría del mestiçagem, una nueva interpretación que favorezca absolutamente sus propios intereses.

Dos eventos, cuyos efectos marcarán el siglo XX brasileño, anticiparán -de manera sintomática en 1922, el año de la conmemoración del centenario de la independencia- a este nuevo Brasil. El primero de ellos, la Semana de Arte Moderna de São Paulo en abril de 1922, deja entrever un cambio cultural, que luego en el transcurso de los años 20 se verá reflejado en manifiestos frecuentemente citados y en las expresiones del arte vanguardista (Schwartz).

El segundo acontecimiento es de carácter absolutamente diferente: también una revolución, en este caso una revuelta que termina trágicamente. Dicho acontecimiento está menos presente en la conciencia histórico-cultural y, a pesar de su carácter trágico, ha sido considerado en repetidas ocasiones como un evento anecdótico en la historia política del país: la Revolta dos 18 do Forte de Copacabana del 16 de julio de 1922. Esta revuelta, que dejó como saldo 17 rebeldes muertos durante el enfrentamiento con las tropas regulares, dio inicio al movimiento tenentista que interviene la historia nacional con la Marcha de la Columna Miguel Costa - Carlos Prestes entre 1925 y 1927, y que jugará un rol decisivo en el golpe de Estado de Getúlio Vargas en 1930.

Si a partir de la Semana de Arte existe una influencia soterrada para la contrucción de la nueva capital Brasília ${ }^{2}$, también existe una correspondencia velada entre la Revolta dos 18 do Forte de Copacabana y el golpe militar de 1964: dos proyectos extremos de cambio bajo circunstancias totalmente opuestas.

2 El 21 de abril de 1960, el presidente Kubitschek inaugurará la nueva capital Brasília, a pocos kilómetros de donde el 7 de septiembre de 1922 el presidente de la época, Epitacio da Silva Pessoa, había colocado la primera piedra para la construcción de una nueva capital. Brasília será la realización de un sueño modernista. El planificador urbano de esta obra, Lúcio Costa, y su principal arquitecto, Oscar Niemeyer, concretarán lo que los artistas de la época del modernismo habían soñado. 
El paralelismo histórico entre el modernismo y el "tenentismo", por un lado, y entre dos de sus efectos tardíos - la construcción de Brasília (1960) y el golpe militar (1964)-, por otro, de los cuales un número considerable de antiguos tenientes fueron responsables -no es una coincidencia. Estos movimientos tienen más en común de lo que pareciera: en ambos se repite una glorificación de la nación y de lo nacional, ambos luchan contra enemigos parecidos: hacia el exterior, la dependencia de Brasil de los países industrializados y del imperialismo; y hacia el interior, el poder de las oligarquías tradicionales. Ambos movimientos utilizan estrategias similares - por cierto, en ámbitos completamente diferentes: el área cultural y aquella de la lucha política directa-: acciones rupturistas, el choque, la intervención violenta y, en el caso de los militares, el golpe militar. Ambos buscan "acercarse al pueblo" y redescubrir, reinventar "lo nacional", forjando una identidad que fortalezca la unidad nacional mediante la creación del mito de una nación.

En la etapa de transformaciones violentas, marcada por los drásticos procesos de modernización de los años 20, destacan en el ámbito cultural los manifiestos literarios, las novelas y el arte vanguardista y, a nivel político, la Gran Marcha de Prestes (1925-27), que atraviesa miles de kilómetros al interior del país, con el objeto de movilizar al pueblo en contra del poder de los latifundistas.

Dichos cambios culminan con la revolución de 1930, que supone el fin de la primera República, la República Velha, y da inicio a la era de Getúlio Vargas, quien entre 1937 y 1945 estará al mando del Estado Novo, un Estado populista de rasgos claramente fascistas, pero que sin embargo practicará el realismo político, en el sentido de aprovechar las ventajas económicas y políticas que trae consigo el apoyo a los Estados Unidos en la Segunda Guerra Mundial. Brasil se convertirá en el único país latinoamericano cuyas tropas participarán en los acontecimientos bélicos de Europa (Italia). Los cambios de los años 20 a nivel nacional e internacional y el fin de a República velha se convierten en un desafío para la burguesía brasileña y sus intelectuales, en el sentido de replantearse y redefinirse a sí mismos y a su país, con el fin de demostrar que éste sí cuenta con el potencial étnico y cultural para llegar a ser una nación moderna aún bajo condiciones tropicales y con un pasado colonialista portugués.

Estos son los antecedentes por los cuales en este trabajo se compararán a continuación dos de los ensayos más influyentes sobre la cultura brasileña del siglo XX: Gilberto Freyre: Casa-grande \& Senzala. Formação da Familia Brasileira sob o regime da Economia Patriarcal, (1933) y Sérgio Buarque 
de Holanda: Raízes do Brasil, (1936)3. Se trata de dos interpretaciones del país que no podrían ser más distintas la una de la otra.

Gilberto Freyre nace en 1900 al noreste de Brasil, en Recife, y sus antepasados pertenecían a la antigua aristocracia rural de Pernambuco. Inicia sus estudios universitarios en 1918 en la Universidad Bautista de Baylor en Tejas, EE.UU., y continúa éstos en la Universidad neoyorquina de Columbia. Su profesor, el antropólogo Franz Boas, ejercerá una gran influencia sobre él. En su doctorado titulado Social Life in Brazil in the Middle of the 19th Century, desarrollará los fundamentos para lo que sería su tesis principal en Casa-grande \& Senzala, su libro más leído: el mestiçagem entre los amos portugueses y los esclavos africanos como una forma de convivencia, en la que los antagonismos sociales y culturales encuentran su equilibrio (Ventura y Costa).

Tras sus estudios en los Estados Unidos, Gilberto Freyre retorna al noreste brasileño. La revolución de 1930 lo obliga, en su calidad de estrecho colaborador del gobernador de Pernambuco, quien había apoyado al presidente derrocado Washington Luiz, a exiliarse en Portugal en compañía del gobernador. Allí comenzará a elaborar el manuscrito para Casa-grande \& Senzala. Esto quiere decir que dicho estudio será escrito a partir de una disputa directa y un conflicto con las fuerzas políticas y militares de la Alianza Liberal, que fuera apoyada por el movimiento tenentista, al cual pertenecían los principales integrantes de la Coluna Prestes. Contrariamente al proyecto de cambio violento del país de los partidos progresistas del sur, Gilberto Freyre apostará a la fuerza cultural y políticamente dinámica del mestiçagem, que en los últimos siglos sentó las bases de un Brasil auténtico y que, según él, entrega todas las condiciones para un Brasil realmente brasileño, que forjará su futuro a partir de su propio pasado y que creará un orden social sobre la base de sus propias prácticas sociales: una renovación no a partir del sur urbano, industrializado y europeizado que representa São Paulo -ni tampoco de la Semana de Arte de 1922-, sino a partir del potencial cultural y ecológico del noreste del país. Ya en su estudio de 1925, en su Livro do Nordeste, Gilberto Freyre había desarrollado dicha posición, defendiéndola luego en su Manifesto Regionalista en el Primeiro Congresso Regionalista realizado en 1926 en la ciudad de Recife (Ventura). A partir de 1930, primero en el

\footnotetext{
El apellido Holanda puede encontrarse escrito también como Hollanda, su forma original, pero que Sérgio Buarque de Holanda reemplazó por Holanda al firmar. En la primera edición de Raizes do Brasil el apellido del autor ya aparece escrito de esta forma.
} 
exilio en Portugal y posteriormente durante una nueva estadía en EE.UU., Freyre profundizará esta tesis, orientando a ésta su trabajo científico, que convierte el mestiçagem en la base de la cultura brasileña. La revalorización del mestiçagem en contra de las teorías raciales del siglo XIX se había iniciado ya a finales de aquel siglo. Sus primeros efectos se vieron en la teoría del branqueamento, defendida por científicos e intelectuales influyentes como Sílvio Romero. Posteriormente, la mezcla con la población blanca, así como la inmigración de población blanca (en su mayoría hombres), conllevará inevitablemente un branqueamento racial y, por consiguiente, la "mejora racial" de la población ${ }^{4}$. Si bien implícitamente esto sigue siendo una teoría racial, que le atribuye a la población blanca un potencial de desarrollo mayor, constituye al mismo tiempo una rectificación de la teoría racial clásica, según la cual cualquier tipo de mestiçagem necesariamente supone decadencia y ruina. En dicha teoría se vislumbra un primer alejamiento desde una teoría racial positivista y determinada meramente por elementos biológicos, hacia un concepto de raza, en el cual la "raza" se constituye al mismo tiempo por prácticas históricas, sociales y culturales. Según ello, el mestiçagem no solo es una mezcla biológica, sino que se convierte en un aporte histórico y cultural que distingue a la colonización portuguesa de las colonizaciones española e inglesa en las otras regiones de América.

Esta revaloración del mestiçagem desde una connotación discriminatoria a una de fortaleza étnica y cultural, incluso de superioridad, está relacionada con una valorización general de la identidad de los intelectuales latinoamericanos, que se verá respaldada por los dos acontecimientos acaecidos a comienzos del siglo XX, ya mencionados anteriormente: la Primera Guerra Mundial y la Revolución rusa. A ello cabe agregar la Revolución mexicana, como un importante acontecimiento regional. Así también resulta coherente el primer gran ensayo en el que el mestizaje se describe como proyecto proactivo, que se presenta no solo como libre de toda sospecha de decadencia, sino como programa para una futura humanidad, tal como lo formula el mexicano José Vasconcelos en La raza cósmica (1925). En la última parte de su ensayo, Vasconcelos hace referencia precisamente a Brasil, pero no tanto porque

\footnotetext{
Al respecto, Lilia Moritz Schwarcz señala: “Também o antropólogo Roquete Pinto, como presidente do I Congresso Brasileiro de Eugenia, que aconteceu em 1929, previa, anos depois e a despeito de sua crítica às posições racistas, um país cada vez mais branco: em 2012 teríamos uma população composta de $80 \%$ de brancos e $20 \%$ de mestiços; nenhum negro, nenhum índio". Schwarcz, Lilia Moritz, Nem branco nem preto, muito pelo contrário... (26).
} 
la mezcla racial ya se hubiera producido allí -en ese caso, según su teoría del mestizaje, éste ya ocuparía otro lugar en la jerarquía de las potencias mundiales-, sino debido a su potencial en materia de recursos naturales. José Vasconcelos es invitado a la celebración con motivo del centenario de la independencia. Por cierto, en la descripción de su viaje, no hace mención alguna de la Semana de Arte, pero sí de una visita a las cataratas de Iguazú.

Gilberto Freyre reinterpreta en forma "realista" la mezcla de razas como programa de una humanidad del futuro, limitándola a un proyecto nacional, cuyos cimientos concretos se encuentran en la Casa-grande en las prácticas culturales coloniales, en las formas de producción (explotación de plantaciones y el Engenho) y en la vida cotidiana. Sin duda alguna, esta revelación y la demostración de las prácticas del mestiçagem en la vida cotidiana de todas aquellas personas que comparten ese espacio central de Casa-grande \& Senzala constituyen la fortaleza y el poder persuasivo de dicho libro. El mismo Gilberto Freyre lo consideró más un estudio literario que uno sociológico o antropólogico (Ventura 45 y Darcy Ribeiro, cit. en la reseña de Lila Moritz Schwarcz en el presente volumen). Este libro saca su poder del convencimiento no tanto de lo sistemático de la investigación científica, sino de la representación literaria, en la que de hechos aislados, probados históricamente, se generan conclusiones universales formuladas de manera brillante. En este sentido, Casa-grande \& Senzala constituye aún hoy en día un libro apasionante y persuasivo. Tal como en todas aquellas obras científicas notables cuyas teorías se han vuelto insostenibles, pero que aun así leemos porque constituyen un aporte tanto a nuestra visión sobre la historia, como al entendimiento y análisis de las razones y argumentos por los que estas obras fundamentan y defienden dichas teorías, también sucede en el caso de Gilberto Freyre que su imagen de la convivencia en la Casagrande (allí era donde se producía la convivencia -el espacio dominado por colonizadores y no en la Senzala, el espacio (limitado) de los colonizados), puede interpretarse como una genial autojustificación de las prácticas sociales de la sociedad colonial portuguesa en el noreste de Brasil. Mediante ésta se logran -desde la perspectiva del colonizador-fundamentalmente dos cosas: 1) evitar un conflicto abierto y permanente entre el colonizador y el colonizado (los quilombos y sobre todo el de Palmares ${ }^{5}$ se mencionan al margen, pero 
en ningún momento se tematizan), y 2) evitar la negación completa del otro, del colonizado, que en última instancia supone una autonegación parcial del colonizador, en la medida en que a éste le unen numerosas prácticas comunes con el colonizado. El amplio reconocimiento del aporte de la cultura de los esclavos africanos a la cultura de la sociedad colonial portuguesa y luego a la creación de una cultura brasileña autónoma, contribuye evidentemente a la revalorización de la cultura brasileña. No se trata tanto de una estrategia de encubrimiento de las prácticas coloniales, sino más que eso: de una estrategia de consecuente revaloración del colonizador y, por consiguiente, de la cultura brasileña en su totalidad.

Aquí reside la gran ambivalencia del término -y de las prácticas- del mestiçagem: sin duda, constituye una práctica que distingue por principio a las sociedades coloniales de las metrópolis, siendo forjadora de identidad para América Latina, especialmente para Brasil, pero también constituye una práctica sujeta a la hegemonía del colonizador: él es quien define dónde y cómo se produce ésta. Las plantaciones son lugares de propiedad del colonizador, el espacio de la Casa-grande ha sido construido por él, y él decide quién accede a éste o es excluido del mismo. Las reglas de la convivencia las establece el colonizador, los espacios del colonizado están limitados y estrictamente controlados: la cocina, el contacto con los hijos e incluso la esfera más importante del mestiçagem: las relaciones sexuales entre los portugueses y las mujeres indígenas en primer lugar y en segundo lugar con las esclavas ${ }^{6}$. Se trata claramente de una relación de género definida por las estructuras de poder, pero que en ninguna parte del libro es explicitada, sino más bien constituye una loa a la sensualidad y al encuentro placentero entre el colonizador y la colonizada -sobre todo en el cuarto capítulo " $\mathrm{O}$ escravo negro na vida sexual e de familia do brasileiro" (301-380). De dicha relación queda excluido - con la mayor naturalidad- el segmento masculino de los colonizados. Ellos deben entregar sus mujeres al colonizador blanco sin contraprestación alguna. Pero tampoco las mujeres blancas participan en este mestiçagem. Las contrapartes de dicho mestiçagem son el hombre blanco y en primer lugar el gran número de mujeres indígenas, luego las esclavas

\footnotetext{
“A luxúria dos indivíduos, soltos sem família, no meio da indiada nua, vinha servir a poderosas razões de Estado no sentido de rápido povoamento mestiço da nova terra [...] O ambiente em que começou a vida brasileira foi de quase intoxicação sexual [...] $\mathrm{O}$ europeu saltava em terra escorregando em índia nua; os próprios padres da Companhia presicavam descer com cuidado, senão atolavam o pé em carne" (93).
} 
y finalmente las mulatas. Desde esta perspectiva, se le atribuye al concepto del branqueamento una cierta lógica cínica, ya que esa dominación del hombre blanco debe efectivamente conducir, en la práctica del mestiçagem, a un branqueamento.

Paralelamente esta práctica del mestiçagem se refleja en otro fenómeno, considerado tanto por Gilberto Freyre -al igual que, como veremos más adelante, por Sérgio Buarque de Holanda- como algo sintomático para la sociedad brasileña (y seguramente también para las sociedades latinoamericanas en general): la clara primacía de las relaciones personales sobre aquellas institucionalizadas y definidas por reglas y leyes objetivas. La práctica sexual sobre la que se basa el mestiçagem llevó solo en sus inicios a la fundación de familias. Posteriormente, con la llegada de mujeres portuguesas y bajo la presión social de contraer matrimonio, sobre todo entre familias portuguesas, los matrimonios mestizos pasaron a ser una excepción. Si bien la institución "matrimonio" existía de manera formal, en la práctica cotidiana no era precisamente la instancia donde se producía el mestiçagem. Por consiguiente, con esta relación institucionalizada entró a competir en la vida cotidiana una serie de relaciones personales, con efectos sostenibles en el tiempo y con múltiples consecuencias, que por cierto incluso en la esfera más íntima eran definidos por la jerarquía social. Con toda la sensualidad celebrada por Gilberto Freyre, los encuentros eran siempre entre colonizador y colonizada, amo y esclava o mulata directamente dependiente, y no entre dos individuos que pudieran elegir libremente. Incluso allí donde la personalidad del amo blanco se sitúa, en su pasión, más allá de cualquier orden institucional y más allá de todas las reglas del Estado y la Iglesia, seguirá representando el orden colonial, incluso también cuando sus intereses individuales y particulares se contrapongan a éste. En este espacio puede y debe producirse lo que Sérgio Buarque de Holanda denominará cordialidade: la competencia entre las reglas sujetas a una racionalidad institucional (trátese de la familia con su orden, trátese del Estado o la Iglesia con sus leyes y mandamientos) y las relaciones sociales definidas por la personalidad del patriarca (el más fuerte) y sus afectos, preferencias y aversiones. La Casa-grande es el reino de dichas relaciones. Las instituciones oficiales, al inicio la Iglesia y el rey o virrey, más tarde, a partir de la independencia, el Estado brasileño y sus emperadores son aquí absolutamente marginales. Desde esa perpectiva, el mestiçagem se convierte también en una de las razones más importantes para la primacía de las relaciones personales sobre aquéllas institucionalizadas, un fenómeno que antropólogos brasileños también diagnosticarán todavía a finales del 
siglo XX para la sociedad brasileña (DaMatta 1997). Se trata -aún en el presente- de la coexistencia de dos registros entre los cuales no existe una jerarquía clara en pro de las relaciones racionales institucionalizadas, como en las sociedades industrializadas del norte con un orden estatal claramente definido y sus leyes, sino en las que el sujeto individual a veces se comporta como "personalidad" y otras como ciudadano, dependiendo de lo que mejor corresponda a sus intereses (id. 226-238).

Por lo tanto, el mestiçagem como práctica social de una convivencia no implica solamente la conservación del orden colonial y de un sistema de dominación, como lo establece Antonio Cornejo Polar en su crítica al término mestizaje ${ }^{7}$, sino también un orden social en el que se favorecen relaciones personales arbitrarias, pasando la racionalidad institucional a un segundo plano.

Considerar las relaciones sexuales entre el descubridor y colonizador y las mujeres indígenas y africanas el fundamento del mestiçagem, que a su vez es la base de la brasilidade -una sociedad y cultura brasileña auténticatiene como consecuencia que dicha cultura se entienda a sí misma como una cultura en la que la reproducción constituye un acto "placentero" de la naturaleza ${ }^{8}$, en la que la riqueza de la cultura tropical ofrece un medio de subsistencia disponible gratuitamente y en la que el trabajo constituye un fenómeno de menor importancia. Ello se demuestra en la ilustración anexa a Casa-grande \& Senzala, en la que el ingenio -el lugar de producción-y las plantaciones, es decir los dos lugares donde los esclavos hombres realizan el trabajo principal del que vive la Casa-grande como totalidad, solamente se aprecian al margen. En esta abundancia tropical, el trabajo parece estar de más; por esta razón, también aquellos que lo realizan pueden quedar excluidos

\footnotetext{
"Varias veces he comentado que el concepto de mestizaje, pese a su tradición y prestigio, es el que falsifica de una manera más drástica la condición de nuestra cultura y literatura. En efecto lo que hace es ofrecer imágenes armónicas de lo que obviamente es desgajado y beligerante, proponiendo figuraciones que en el fondo sólo son pertinentes a quienes conviene imaginar nuestras sociedades como tersos y nada conflictivos espacios de convivencia [...] Añado que -pese a mi irrestricto respeto por Ángel Rama- la idea de transculturación se ha convertido cada vez más en la cobertura más sofisticada de la categoría de mestizaje. Después de todo el símbolo del ‘ajiaco' de Fernando Ortiz que reasume Rama bien puede ser el emblema mayor de la falaz armonía en la que habría concluido un proceso múltiple de mixturacion" (Cornejo Polar 867).

Como lo describe irónicamente Mario de Andrade en los primeros capítulos de su libro de Macunaíma, en los que la pereza y la copulación se muestran como la ocupación principal de la tribu de Macunaíma, el héroe sin carácter alguno.
} 
de la imagen. La loa al ocio -según Gilberto Freyre las múltiples formas de vida en la hamaca, desde el mestiçagem sexual gozoso hasta los traslados por esclavos en hamacas sostenidas por barras- es solamente la otra cara de un tema literario que se repite en la literatura brasileña en múltiples variaciones, como en el caso del notable poeta Olavo Bilac: "O brasileiro é naturalmente triste, são as três raças que contribuíram para a sua formação". También el subtítulo del ensayo de Paulo Prado, publicado en 1928, Retrato do Brasil: Ensaio sobre a tristeza brasileira, llama la atención sobre la tristeza tropical. Si dicha tristeza debiera interpretarse como una pérdida de identidad cuya causa estaría en el mestiçagem, o si se trata de una forma secular de la acedia, del no querer hacer nada, de la desidia del corazón, que siempre va acompañada de inactividad - preguiça de Macunaíma-, no es un tema a profundizar aquí.

Sea como fuere, en la Casa-grande \& Senzala de Gilberto Freyre se muestra el mundo tropical desde su lado más seductor. El tropicalismo y el mestiçagem se presentan como prácticas culturales dignas de vivir, frente a un mundo capitalista de alienación. Gilberto Freyre no abandonará esa orientación, sino más bien le dará continuidad en su libro tras la Segunda Guerra Mundial, New World in the Tropics: the Culture of Modern Brazil (1959) (una versión revisada de Brazil, an Interpretation (1945)) que fuera publicado primero en EE.UU. Lilia Schwarcz señala al respecto: "Novo mundo nos trópicos é, assim, um estudo sintético e no seu conjunto até otimista: longe do jargão do 'país-perdido' surge a idéia de vanguarda do mundo e de uma 'democracia dinamicamente étnico-cultural"” (Schwarcz, Gilberto 316). Y agrega: "É o próprio Freyre quem destaca e glorifica esse povo que foi, no limite e em seu entender, responsável pela formação de uma sociedade e de uma cultura repostas nas suas singularidades." (Schwarcz, Gilberto 316-317).

El Brasil de Gilberto Freyre se determina a partir de la privacidade, sobre ello llama la atención también Lilia Schwarcz de manera incisiva en sus estudios. En cambio, la esfera pública aparece como secundaria. A pesar de importantes diferencias, en la Casa-grande \& Senzala se identifican considerables coincidencias con el segundo gran estudio de aquellos años sobre Brasil que, al igual que el estudio de Gilberto Freyre, sigue siendo hasta el día de hoy un clásico de la literatura brasileña: Raízes do Brasil de Sérgio Buarque de Holanda9.

9 En 2013 fue publicada una nueva versión de la traducción al alemán con un epílogo del sociólogo brasileño Sérgio Costa, en el que éste señala: "Dos ensayos de los años 30 
Sin embargo, Sérgio Buarque de Holanda escribe desde una posición totalmente diferente y habla -al parecer-sobre un Brasil totalmente distinto. Proviene de una familia de clase media de São Paulo, la ciudad que en aquellos tiempos comenzaba a convertirse en la ciudad más moderna y económicamente más poderosa de Brasil. En ese entonces contaba la ciudad con aproximadamente 600.000 habitantes (en 1880 eran tan solo alrededor de 80.000), de éstos más de un tercio eran emigrantes sobre todo europeos, pero también asiáticos. São Paulo se convierte en el escenario principal del movimiento modernista y, por consiguiente, en la ciudad de la Semana de Arte de 1922. En una entrevista otorgada en 1982, Buarque de Holanda (1982) reconoce su cercanía al movimiento modernista, en el que los negros por primera vez se habrían convertido en sujetos del arte. Aquí comienza a vislumbrase una de las grandes diferencias entre G. Freyre y S. Buarque de Holanda: mientras el primero escribe sobre el mundo cotidiano común entre blancos y negros -aun cuando fuera desde la perpectiva del colonizador-, para los modernistas la cultura negra pasará a convertirse en objeto de su arte.

También la formación de Sérgio Buarque difiere mucho de la de Freyre: en el año de la revolución de 1930 se encuentra en Berlín como corresponsal extranjero del periódico O Jornal, desde donde comenta elogiosamente la elección de Júlio Prestes como presidente (Buarque de Holanda 2011), cuya asunción, por cierto, es impedida por Gétulio Vargas y la Revolução de 30. Durante sus años de estadía en Berlín (1929-1931), asiste a las clases del historiador Meinecke y lee los estudios de Ernst Kantorowicz, Leopold von Ranke, Carl Schmitt, Georg Simmel, Ferdinand Tönnies, Werner Sombart y particularmente de Max Weber (Costa 242), al que se referirá luego en Raízes do Brasil. Tras su retorno a Brasil se instalará en Río de Janeiro, incorporando parte de sus registros de Alemania en dicho ensayo, que será publicado en 1936.

En forma similar a Gilberto Freyre, Sérgio Buarque de Holanda también intentará comprender el Brasil de ese entonces a partir de la época colonial (Raízes do Brasil, capítulos 1-4). No obstante renunciará a cualquier teoría racial, apoyándose en sus profesores alemanes - para los que cualquier forma de sociología argumentada mediante la pertenencia a una raza constituía

permitieron reinventar intelectualmente la nación brasileña, influyendo decisivamente sobre la imagen y autoimagen que la marcan hasta el día de hoy". Hablamos de Casa-grande \& Senzala y Raizes do Brasil. 
una postura fascista o al menos cercana a ésta- proponiendo derivar el desarrollo social de Brasil no a partir de una relación entre razas, sino desde la relación individuo, sociedad y Estado, una dimensión que Gilberto Freyre deja completamente de lado. El fenómeno en el que según Sérgio Buarque de Holanda se expresa de la manera más clara la singularidad de la relación individuo, sociedad y Estado, la relación singularidad-generalidad y leyes en la historia de Brasil, es el de la cordialidade. Sin embargo, a diferencia de lo que se podría suponer a primera vista, se está haciendo referencia allí a una estrategia que refuerza estructuras de poder existentes. El homem cordial, refiriéndose al brasileño, también al brasileño del siglo XX, representa el penúltimo capítulo de Raízes do Brasil. Las primeras reflexiones al respecto se encuentran en el artículo "Corpo e alma do Brasil: ensaio de piscologia social", publicado en 1935, en el que Buarque de Holanda hace suyo el término introducido por Ribeiro Couto de homem cordial, reinterpretándolo por cierto de manera crítica. Tema central del análisis de Buarque de Holanda es, según él, la contradicción característica para Brasil entre las relaciones personales y las relaciones de poder creadas a partir de éstas, por un lado, y las relaciones definidas y reguladas por un orden estatal y una legislación objetiva, por otro. Ambos órdenes exigen y forjan individuos absolutamente diferentes y, por consiguiente, también subjetividades completamente distintas, un término que no encontramos en Buarque de Holanda, pero que hoy en día nos es familiar. Sin embargo, dado que la realidad social de Brasil está marcada sobre todo por las relaciones personales, manteniéndose al mismo tiempo el orden estatal oficial y sus leyes relativamente inoperantes e impotentes, la individualidad brasileña está determinada sobre todo por las dependencias personales que deben ser creadas frente a las demás personas y dentro de las cuales se desenvuelve. Lo que suaviza -podría decirse así en forma figurada- esas relaciones personales de poder y no reguladas por leyes objetivas, es la cordialidade. El individuo que se ajusta a dicha sociedad es el homem cordial. Con ello de ninguna manera se está haciendo referencia a algún tipo de predisposición "natural", sino más bien todo lo contrario, a una conducta generada por circunstancias históricas y sociales que pretende hacerse pasar por natural o intenta parecer natural, la manera como Sérgio Buarque de Holanda redefine el homem cordial de Riberiro Couto (1932). Para éste, el homem cordial de América es -sobre todo en Brasil - una contribución de América Latina a la civilización, alineándose de este modo con otras propuestas de aquellos años para convertir a América Latina en "exportador" de civilización y no solamente de materias primas (véase Oswald de Andrade y José Vasconcelos). 
Sérgio Buarque de Holanda deducirá esa cordialidade a partir de formas ritualizadas de la cortesía, de las boas maneiras (57), que siempre son el resultado de obligación y control, como lo constata Norbert Elias en su obra princial El proceso de la civilización (Der Prozess der Zivilisation), escrito en la misma época. "Nenhum povo está mais distante dessa noção ritualista da vida que o brasileiro. Nossa forma comum de convívio social é no fundo justamente o contrário da polidez" (60). Si bien la cordialidad puede parecer a veces cortesía, ello se debe a que ésta hace el intento de ritualizar las expresiones espontáneas de la cordialidad. No es la cordialidad la que adopta formas de la cortesía, sino al revés, es la cortesía la que intenta mostrarse como cordialidad espontánea. La cortesía es más bien una actitud defensiva frente a la sociedad. Es algo aparente del inividuo, más bien un mecanismo de defensa, que permite a cada persona esconder sus sentimientos y sensaciones (60). En la "psicología" de nuestro homem cordial se contraponen precisamente los mecanismos sicológicos: "No 'homem cordial' a vida em sociedade é de certo modo uma libertação do verdadeiro pavor que ele sente em viver consigo mesmo, em apoiar-se sobre si próprio em todas as circunstâncias da existência" (60). El modelo del individuo responsable de sí mismo, autónomo y que se define a partir de sí mismo le provoca temor al homem cordial. Su individualidad es precisamente la parte social, vivir en los otros (um viver nos outros). En cambio Sérgio Buarque cita en forma crítica el Zaratustra de Nietzsche. "Vuestro mal amor a vosotros mismos hace de la soledad una cárcel" (78), señalando que ese tipo de ser humano que carece de amor por sí mismo es el brasileño al que le falta una "personalidade fortemente homogênea e equilibrada em todas as suas partes" (61). Es decir, el homem cordial es considerado como un fenómeno social y no como expresión de cordialidad espontánea y, más allá de ello, en forma absolutamente crítica, como un individuo que se desvía de sí mismo a través de la alienación. Con ello se convierte en lo contrario del hombre cordial, quien a través de su cordialidad se protege de los otros. Las formas de cordialidad se aceptan en el trato en Brasil solamente cuando no existe la posibilidad de un "convívio mais familiar" (61). Frente a la costumbre portuguesa de atribuirle valor a los títulos de honor, Brasil se distingue por el "desejo de estabelecer intimidade" (61). No obstante, Sérgio Buarque de Holanda no considera esa apertura a lo social como un modelo a seguir: "Pode-se supor que essa aptidão para o social constituísse uma tendência aproveitável para a organização coletiva. É um engano" (63). Como esa conducta social cordial constituye en realidad una evasión de un actuar individual autónomo, 
seguro de sí mismo y responsable, dicha conducta social se compensa con la expectativa de leyes rigurosas del Estado: "Para nós [...] é a rigidez, a impermeabilidade e a perfeita homogeneidade da legislação [contrariamente a la práctica en Inglaterra, $\mathrm{HN}$ ] que nos parecem os requisitos sine qua non de toda disciplina social. [...] Aí reside o principal fundamento de nosso tão acentuado estatismo" (63-64). Es decir, de las leyes rigurosas del Estado se espera que compensen la responsabilidad social que el homem cordial no está dispuesto a asumir. Sin embargo, el Estado brasileño no fue durante el Imperio un estado despótico, ni tampoco lo es en el presente. Fue uno de los primeros países que abolió la pena de muerte tras un largo tiempo en que ya no era aplicada. Finalmente, la consecuencia de ello es -como lo destaca Sérgio Buarque de Holanda haciendo referencia a una larga cita del publicista Alberto Torres- la profunda separación entre política y vida social, es decir, también una profunda separación entre la nación y la clase que se ha consagrado a la política. "A política é, de alto a baixo, um mecanismo alheio á sociedade, perturbador de sua ordem, contrária a seu progresso, governos, partidos e políticos sucedem-se e alternam-se, levantando e combatendo desordens, criando e destruindo coisas inúteis e embaraçosas" (cit. en 66).

Esta separación entre nación y política es para Sérgio Buarque de Holanda la consecuencia de la contradicción descrita más arriba entre la conducta del homem cordial, cuya cordialidad no está dispuesta a asumir responsabilidades, y la expectativa de que las leyes estatales hagan lo que les corresponde para ordenar la sociedad. No obstante, la letra muerta (a letra morta) no puede guiar el destino de los pueblos, es decir, también las mejores leyes quedarán sin efecto si la práctica social (del homem cordial) no está concebida para respetar éstas en la vida cotidiana. Allí también ve Sérgio Buarque de Holanda la causa del fracaso de la "ideologia impessoal e antinatural do liberalismo democrático" (66) en Brasil.

Só assimilamos efectivamente esses princípios até o ponto em que coincidam com a negacão pura e simples de uma autoridade incómoda, em que confirmava nosso instintivo horror às hierarquias e em que nos permitiam tratar com familiaridade aos governantes. A democracia no Brasil foi sempre um lamantável mal-entendido. Uma aristocracia rural e semifeudal importou-a e tratou de acomodar-se como póde aos sus preceitos que tinham sido justamente a bandeira de combate da burguesía europeia, e isso somente porque esses preceitos pareciam os mais acertados para os tempos e eran exaltados nos livros e nos discursos (66). 
Roberto Schwarz repetirá ésto de manera muy similar en su muy citado y discutido ensayo "As idéias fora do lugar" poco más de 40 años más tarde. Aquí Sérgio Buarque de Holanda explica por qué esas ideas están "fora do lugar": un sujeto que se entrega a la cordialidade puede aceptar tales reglas abstractas y objetivas tanto en aquellos casos en que éstas no están comprendidas en su estrategia de la cordialidade, como en aquéllos en que el individuo pretende dejarlas a cargo del Estado, con el que, en lo posible, no quisiera tener nada que ver. Es decir, según la interpretación de Sérgio Buarque de Holanda, las ideas del liberalismo, incluso en la parte moderna de Brasil, en el que el Estado se ha establecido como institución, nunca podrían llegar a ser acogidas por individuos que estuvieron dispuestos a orientar sus propias acciones y su práctica social en virtud de éstas. Para qué hablar del mundo de la Casa-grande \& Senzala.

Lo que pudiera objetarse de los comentarios de Sérgio Buarque Holanda es que éstos son válidos solamente para una pequeña parte de la población brasileña, aquella para la que el Estado y sus leyes objetivas, pero al mismo tiempo abstractas, son una opción. Tal Estado, sin embargo, prácticamente no existía en el Noreste del país, como lo pone en evidencia Gilberto Freyre en Casa-grande \& Senzala. Las relaciones sociales estaban determinadas y dominadas allí por las relaciones personales. La clara separación entre la esfera pública y la privada, en la que de la primera se espera que acepte las reglas de la racionalidad generales, haga posible y fomente un control recíproco de aquellos que se desenvuelven en ella y la esfera privada donde son efectivas las dependencias personales -sean éstas familiares o amistosas-, constituye un fenómeno de la modernidad, del Estado moderno y del mercado y su orden que se legitima como racional. Dicho Estado comienza a imponerse lentamente en el sur industrializado de Brasil y solo después en el Noreste, en donde el poder de los coroneis y de los clanes familiares es, en gran medida, hasta la segunda mitad del siglo XX, inquebrantable. Allí son las dependencias personales las que no solo determinan la esfera privada, la intimidad -como lo expresa Lilia Moritz Schwarcz-, sino también dominan el acontecer social en su totalidad, la política, la economía y el aparato administrativo. Y ello no se considera "inmoral" o "ilegal", sino "obvio" y "natural". El poder es, bajo estas circunstancias, una institución personal y no una abstracta. Entender éste como instancia abstracta, que se legitima mediante leyes objetivas y que, gracias a su racionalidad puede exigir un reconocimiento general (voluntario), es el resultado de un complejo proceso de transformación hacia la modernidad. 
La sociedad del mestiçagem de la Casa-grande y el Brasil de la cordialidade tienen en común que ambas son la expresión de sociedades premodernas o-quizás también- de prácticas sociales que se han mantenido en una heterogeineidad cultural simultánea a las formas sociales modernas comprometidas con la racionaldiad y las leyes objetivas.

No obstante, no son solamente estas dependencias personales las que caracterizan a la sociedad brasileña en estos relatos tan opuestos. Esto no bastaría como criterio, dado que las dependencias personales han marcado todas las sociedades preindustrializadas. Lo que resulta relevante agregar son las formas que estas dependencias personales -en el caso de Gilberto Freyre, la práctica del mestiçagem, en el caso de Sérgio Buarque de Holanda, la cordialidade-adoptan. Y también aquí encontramos un importante punto en común entre las tan diversas descripciones de Gilberto Freyre y Sérgio Buarque de Holanda: el mestiçagem de la Casa-grande -no precisamente el mestiçagem urbano, que es el resultado de encuentros más o menos casuales, sino un mestiçagem en un espacio claramente definido- es en la descripción de Freyre el resultado de una convivencia no solamente marcada por la sensualidad y el erotismo, sino en la que paralelamente se lleva a cabo un intercambio intenso y creativo de diversas prácticas culturales (prácticas religiosas, costumbres culinarias, tradiciones orales). En otras palabras, es solamente en muy pequeña medida una forma ritualizada de relaciones personales. Precisamente a ello le atribuye Sérgio Buarque de Holanda gran importancia: la cordialidade es lo contrario de la amabilidad ritualizada. La cordialidade intenta precisamente liberarse de rituales. Ambos autores describen la sociedad colonial portuguesa como una forma de convivencia, en la que las ritualizaciones, es decir, las normas establecidas que regulaban las relaciones personales, jugaban un rol menor. Por el contrario, tanto el mestiçagem de Freyre como la cordialidade de Buarque de Holanda se caracterizan por otorgarle un gran espacio a la subjetividad, aun cuando dicha subjetividad es, sin duda alguna, aquélla de los dueños del poder. Éstos no se dejan limitar mediante rituales ni tampoco a través de un orden externo abstracto, sea éste el Estado o la Iglesia. Al mismo tiempo, se trata de una subjetividad que, según Buarque de Holanda, está marcada por el horror às distáncias y el terror do isolamento (Buarque de Holanda, Corpo 62 y 67). No se trata de la subjetividad de un individuo independiente, autónomo, sino de un individuo que para conservar y asegurar su autonomía requiere siempre de un entorno social (familia, amigos, empleados) y del apoyo de éste. Dicha subjetividad está basada en el reconocimiento de la diversidad, de 
la diferencia, y no en un reconocimiento mutuo en igualdad de condiciones. El reconocimiento de la diferencia -cabe enfatizarlo en este contexto- es un argumento extremadamente ambivalente, ya que tradicionalmente la confirmación comprende una desemejanza. Así es como el antropólogo Raimundo Nina Rodrigues insistía expresamente en marcar la diferencia de la "raza negra", exigiendo para ésta -precisamente por su desemejanza e “inferioridad" racial- leyes específicas (Schwarcz 21).

Con seguridad Buarque de Holanda tiene razón cuando expresa sus dudas respecto a las expectativas en relación con la efectividad de leyes abstractas y leyes generales, que no están establecidas en las tradiciones, usanzas y costumbres. Por cierto, las leyes solo pierden su naturaleza abstracta cuando pueden contar con un aparato que garantice su imposición. Construir tal aparato a través de preparación técnica, instituciones y el financiamiento correspondiente, debe ser de interés de un Estado moderno. Este y su sujeto político, el ciudadano seguro y responsable de sí mismo, entran necesariamente en conflicto con una sociedad tradicionalmente orientada a las relaciones personales. La debilidad y precariedad del Estado brasileño en vías de modernización tiene, sin embargo, graves consecuencias para dicho sujeto político. Bajo estas circunstancias, el conflicto entre los derechos del ciudadano y las exigencias que una persona pretenda justificar o imponer a través de sus relaciones personales se resuelve habitualmente mediante el poder de dichas relaciones.

Passa-se [...] de 'cidadão brasileiro' ou de 'individuo', papéis sociais universalizantes que nessas situaçães não dão qualquer direito, a alguém que é 'realmente alguém': deputado, avogado, oficial das Forças Armadas, secretário de Estado etc. Ou, o que é ainda melhor, parente e amigo (isto é, alguém substantivamente ligado a um figurão) (DaMatta, Sabe com 215).

Roberto DaMatta analizó detenidamente este fenómeno sobre la base de la fórmula utilizada recurrentemente en dichos conflictos: "¿Sabe Ud. con quién está hablando?". "O ‘sabe com quem está falando?' [...] é um instrumento de uma sociedade em que as relaçães pessoais formam o núcleo daquilo que chamamos de 'moralidade' (ou 'esfera moral'), e tem um enorme peso no jogo vivo do sistema, sempre ocupando os espaços que as leis do Estado e da economia não penetram" (id. 195).

Por cierto, este espacio en favor de la intervención de la personalidad puede transformarse positivamente en una sociedad horizontal ya no 
jerárquica, sino basada en la igualdad. Y ello, dado que en el conflicto entre una actuación orientada a una racionalidad abstracta y rígida, y una orientada a la responsabilidad personal, se le debe dar preferencia, sin duda alguna, a lo último. Esto es lo que sugieren las ideas de DaMatta:

De fato, quando uma regra burocrática, universalizante e impessoal perde sua racionalidade diante de alguém que alega um laço de filiação, casamento, amizade ou compadrio com outra pessoa considerada poderosa dentro do sistema, estamos efetivamenteo operando com uma situação muito complexa. Pois de um lado temos uma moral rígida e universal das leis ou regras impessoais que surgem com uma feição modernizadora e individualista e são postas em práticas para submeter a todos os membros da sociedade. E, do outro, temos a moralidade muito mais complicada de relaçães sociais imperativas, em que a relação pessoal e a ligação substantiva permitem pular a regra ou, o que dá no mesmo, aplicá-la rigidamente (id. 216-217).

El salirse de las "reglas burocráticas, universalizantes e impersonales" puede tener un efecto muy ambivalente: puede ser una estrategia para la defensa de privilegios $\mathrm{y}$, por lo tanto, de desigualdad, pero también la resistencia a una racionalidad abstracta burocratizada que siempre tendrá su origen -volviendo al concepto de Roberto Schwarz- en un fora de lugar. La ilusión de que las "reglas impersonales", es decir la lógica abstracta del mercado, podrían contribuir a una mayor equidad y justicia, la hemos perdido. En las negociaciones entre sujetos sociales diferentes, las personalidades individuales que se consideran representantes de dichos sujetos, legitimando su actuación con ello, son irrenunciables.

La simultaneidad de estos dos registros, el de lo personal y aquel de las reglas y leyes objetivas, le otorga a la sociedad brasileña precisamente la flexibilidad y la habilidad para negociar en situaciones de conflicto con aquellos registros diferentes, tanto en la esfera privada como en la pública. Bajo las condiciones de una clara primacía de las relaciones personales, como en la sociedad colonial o en un Estado débil y no apoyado por las instituciones correspondientes, existía sin duda alguna el riesgo de transformar "en forma irracional" la relación personal en uso de violencia, pasando por encima de todo derecho y ley. Es el momento en el cual el homem cordial se convierte en tirano, un riesgo en el que claramente Sérgio Buarque de Holanda hace hincapié. Sí, la tendencia hacia tales reacciones irracionales es inherente, por así decirlo, a las estructuras de poder de la sociedad colonial. No obstante, 
cuando luego se producían escaladas, existía una gran disposición a olvidar éstas lo más rápido posible. Brasil no conoce ninguna "leyenda negra", la historia de la sociedad esclavista es narrada por Gilberto Freyre como Casa-grande \& Senzala y cuenta con entusiastas lectores. Lo mismo es válido para la lucha contra la dictadura militar que, 10 años después de los acontecimientos, se describe en el best seller O que é isso companheiro (1979), de Fernando Gabeira -personalmente ex miembro de la guerrilla urbana-, más como una novela de aventura sobre una revuelta juvenil (Ridenti) que una etapa de una transformación nacional e internacional hacia una nueva forma de globalización.

Mestiçagem y cordialidade aparecen en Casa-grande \& Senzala y en Raízes do Brasil como estrategias de convivencia, cuyo origen se encuentra en el pasado colonial, en las cuales las relaciones sociales estaban dominadas por dependencias personales. Ello no quiere decir que no fueran estrategias que se puedan revalorizar y resultar constructivas para una sociedad moderna. Si hacemos una comparación de la sociedad esclavista de Brasil con aquella de los EE.UU., podemos señalar que ya en el pasado - pese a las críticas-dichas estrategias influyeron positivamente sobre la convivencia. La abolición de la esclavitud en Brasil no estuvo vinculada a una guerra civil sangrienta ni tampoco el país conoció el apartheid, dos elementos sobre los cuales llaman la atención ambos autores.

Pese a todas las diferencias, los estudios de ambos autores pueden leerse como una búsqueda de capacidades de desarrollo y de perspectivas para el futuro, inherentes a la misma historia brasileña. En este contexto aparece también la revalorización de la colonización portuguesa, que encontramos en los dos. Solo en una relación positiva y al mismo tiempo crítica con la propia historia es posible encontrar las bases para una vía autónoma hacia la modernidad o descubrir una modernidad propia.

En Casa-grande \& Senzala y en Raizes do Brasil nos encontramos con dos posiciones que causaron un impacto sostenido en el tiempo para la discusión sobre la cultura brasileña del siglo XX. Así como ambos autores analizan el Brasil de los años 30, partiendo de posiciones opuestas y perspectivas diferentes (aun cuando en esos años se encuentran en Sérgio Buarque de Holanda continuamente observaciones muy positivas respecto a la importancia de Casa-grande \& Senzala), también en los años 60 asumirán posiciones opuestas frente a la llegada al poder de la dictadura militar. Gilberto Freyre se pondrá de lado de los militares, reclamando un Estado autoritario y una política de modernización guiada por el Estado, mientras Sérgio Buarque de 
Holanda se incorporará a la oposición intelectual y tras el endurecimiento de la dictadura a través del Ato Institucional 5 y en señal de protesta, abandonará la cátedra en la Universidad de São Paulo (USP). En 1980 se convertirá en uno de los miembros fundadores del Partido de los Trabajadores (PT).

Así como la política populista del Estado Novo puede interpretarse como una confirmación de las explicaciones y reflexiones de S. Buarque de Holanda sobre el homem cordial y la separación entre política y sociedad civil, en la que al mismo tiempo la cordialidade exige un Estado fuerte, la llegada al poder de los militares puede entenderse como una nueva confirmación de dichas tesis. Gilberto Freyre estaría en lo cierto de una manera muy diferente. Desde una perspectiva actual, el concepto del mestiçagem en Casa-grande \& Senzala no es que haya servido de orientación porque refutase la teoría del branqueamento, que nos parece absurda hoy en día, sino porque Gilberto Freyre dio origen en su libro a un estilo argumentativo para la sociología, por el cual ha encontrado -como lo evidencia Susanne Klengel en su artículo en el presente volumen-, reconocimiento científico a nivel internacional. Dicho estilo es una expresión de un "tropicalismo" que se identifica con el mestiçagem cultural que este mismo propaga. En su descripción de la sociedad colonial pareciera que las personalidades se humanizaran a través de su subjetividad; e incluso, al colonizado se le atribuye una subjetividad, lo que un lector crítico muy posiblemente podría poner en duda. No obstante, con ello Gilberto Freyre logra evidenciar la creatividad y productividad de la diversidad cultural de la sociedad colonial -precisamente su mestiçagemque luego, a partir de los años 30, será determinante para la cultura nacional brasileña. A partir de ese momento, y por varias razones, dicha cultura ya no se identificará con las élites, sino con la población, con el mismo "pueblo". Esto es válido tanto para la música y el baile (samba), para la cocina brasileña, la corporalidad celebrada por la cultura playera, que nos recuerda las descripciones de Gilberto Freyre en la Casa-grande \& Senzala, como en general para la vida cotidiana, marcada por la ambigüedad de la cordialidade, que identificó Sérgio Buarque de Holanda de manera crítica. Esta alianza entre los intelectuales y el pueblo, que se repite en los años 50 en la coalición de trabajadores y burguesía progresista, propiciada por la política del Partido Comunista brasileño, alcanzará su apogeo en los años 60, durante la primera etapa de la dictadura militar (1964-1968), en el tropicalismo y tropicália, en la conciliación del modernismo y la cultura popular, pero al mismo tiempo entrará en crisis. Emblemático de ello es la película Terra em Transe de Glauber Rocha, en la que se pone en escena el derrumbe del mito 
de una alianza entre los intelectuales y el pueblo, como lo muestran Roberto Schwarz y también Mónica González García en el presente volumen.

Mediante mestiçagem y codialidade, Gilberto Freyre y Sérgio Buarque de Holanda describieron dos fenómenos y dos prácticas culturales que han marcado en forma determinante la vida cotidiana brasileña hasta nuestros días. En sus estudios dejaron al descubierto los orígenes históricos, culturales, políticos y económicos del mestiçagem hasta la sociedad colonial, llamando la atención paralelamente y en forma enfática sobre la fortaleza de éste (Gilberto Freyre) y en forma crítica sobre la problemática de la cordialidade (Sérgio Buarque de Holanda). Con ello han hecho un significativo aporte para comprender la historia del Brasil del siglo XX, confirmando dicha historia en gran parte estas interpretaciones, tanto en lo positivo como en lo negativo.

Traducido del alemán por Liliana Seelmann G.

\section{BIBLIOGRAFÍA}

Bomfim, Manoel. A América Latina: males de origem. Edição do centenário. Rio de Janeiro: Topbooks, 2005.

Buarque de Holanda, Sérgio. "Corpo e alma do Brasil: ensaio de psicologia social". Escritos colegidos, Livro I 1920-1949. Org. Marcos Costa. São Paulo: Editora Unesp; Fundação Perseu Abramo, 2011. 59-78. Reimpreso de Revista Espelho [Rio de Janeiro], Marzo 1935.

"Dr. Júlio Prestes: Der zukünftige Bundespräsident der Vereinigten Staaten von Brasilien" Duco [Berlín] marzo/abril 1930. Trad. en: Buarque de Holanda, Sergio. Escritos colegidos. Livro I, 1920-1949. Org. Marcos Costa. São Paulo: Editora Unesp; Fundação Perseu Abramo, 2011. 40-42.

"Entrevista". Hispanic-American Historical Reviews 62 (1982): 3-17.

O Homem Cordial. São Paulo. Companhia das Letras, 2012.

Raízes do Brasil. 1936. $20^{a}$ edición. Rio de Janeiro: José Olimpio, 1988.

Cornejo Polar, Antonio. "Mestizaje e hibridez: los riesgos de las metáforas. Apuntes". Revista Iberoamericana LXVIII/200 (Julio-Septiembre 2002): 867-870.

Costa, Sérgio. Nachwort. "Das Brasilien Sérgio Buarque de Holandas”. Wurzeln Brasiliens. Por Sérgio Buarque de Holanda. Frankfurt: Suhrkamp. 2013. 235-270.

Couto, Ribeiro. "El hombre cordial, producto americano". Monterrey: Correo Literario de Alfonso Reyes. Mar. 1932: 169.

Cunha, Euclides da. Os Sertões. 1902. Ed. Leopoldo M. Bernucci, São Paulo: Ateliê Editorial y otros, 2001.

DaMatta, Roberto. "A fábula das três raças, ou o problema do racismo á brasileira". Relativizando. Uma introdução a Antropologia social. Rio de Janeiro: Rocco, 1987. 58-85. 
"Sabe com quem está falando? Um ensaio sobre a distinçao entre individuo e pessoa no Brasil" Carnavais, malandros e heróis. Para uma sociologia do dilema brasileiro. Rio de Janeiro: Rocco, 1997. 179-259.

Freyre, Gilberto. Casa-grande \& Senzala. 1933. Coords. Giucci, Guillermo, Enrique Rodríguez Larreta y Edson Nery da Fonseca. Barcelona; La Habana; Lisboa; Paris; México; Buenos Aires; São Paulo; Lima; Guatemala; San José: ALLCA XX, 2002.

New World in the Tropics: the culture of modern Brazil. New York: Alfred A. Knopf, 1959.

Lisboa, Karen. "Bilder der Alterität, Identitätskonstruktionen: Brasilianer berichten über ihre Reisen in die USA Ende des 19. Jahrhunderts". Brasilien im amerikanischen Kontext. Vom Kaiserreich zur Republik: Kultur, Gesellschaft, Politik. Band 23. Ed. Horst Nitschack. Frankfurt am Main: Biblioteca Luso-Brasileira; Instituto Iberoamericano de Berlín (TFM), 2005. 181-202.

Nietzsche, Friedrich. Sämtliche Werke. Eds. Colli, Giorgio y Mazzino Montinari. Berlin: Walter de Gruyter, 1980.

Mota, Carlos Guilherme. Ideologia da Cultura Brasileira (1933-1974). São Paulo: Editora Ática, 1985.

Prado, Eduardo. A Ilusão Americana. 1893. São Paulo: Editora Brasiliense, 1958.

Prado, Paulo. Retrato do Brasil - Ensaio sobre a tristeza brasileira. 1928. São Paulo: Companhia das Letras, 2008.

Ridenti, Marcelo. “Que história é essa?”. Versões e ficções: o seqüestro da histórica. Aarão, Daniel et al. São Paulo: Editora Fundação Perseu Abramo, 1997.

Rosi, Bruno Gonçalves. “O pensamento político e a política externa brasileiros”. IX Encontro ABCP. 1964-2014: autoritarismo, democracia e direitos humanos. 2014. Web. 26 octubre 2014. <http://www.encontroabcp2014.cienciapolitica.org.br/>.

Schwarcz, Lilia Moritz. "Gilberto Freyre: adaptação, mestiçagem, trópicos e privacidade em Novo Mundo nos trópicos". Gilberto Freyre e os estudos latino-americanos. Eds. Lund, Joshua y Malcolm McNee. Pittsburgh: Instituto Internacional de Literatura Iberoamericana, 2006. 305-334.

Nem branco nem preto, muito pelo contrário. Cor e raça na sociabilidade brasileira. São Paulo: Claroenigma, 2012.

Schwartz, Jorge. Las vanguardias latinoamericanas. Madrid: Edición Cátedra, 1991.

Schwarz, Roberto. “As idéias fora do lugar". Ao vencedor as batatas: forma literária e processo social nos inícios do romance brasileiro. São Paulo: Editora 34; Duas Cidades, 2012.

Vainfas, Ronaldo. "Sexualidade e cultura em Casa-Grande \& Senzala". Casa-grande \& Senzala. Por Gilberto Freyre. Coords. Giucci, Guillermo, Enrique Rodríguez Larreta y Edson Nery da Fonseca. Barcelona, La Habana; Lisboa; Paris; México; Buenos Aires; São Paulo; Lima; Guatemala; San José: ALLCA XX, 2002. 711-785.

Vasconcelos, José. La Raza Cósmica. 1925. México: Colección austral, 1986.

Ventura, Roberto. Casa Grande e Senzala. Sao Paulo: Publifolha, 2000.

Vianna, Oliveira. Populações meridionais do Brasil. 1920. Rio de Janeiro: Paz e Terra, 1973. 